\title{
Developments in Technology-Delivered Psychological Interventions
}

\section{Desarrollos en Intervenciones Psicológicas utilizando la Tecnología}

Recibido: noviembre 1 de 2011 | Revisado: marzo 2 de 2012 | Aceptado: julio 21 de 2012

\author{
DEREK RICHARDS * \\ University of Dublin, Trinity College, Dublin, Ireland \\ Universidad Antonio Nariño, Bogotá, Colombia
}

doi:10.11144/Javeriana.UPSY12-2.dtdp

Para citar este artículo: Richards, D. (2013). Developments in technology-delivered Psychological interventions. Universitas Psychologica, 12(2), 571579.

* Universidad Antonio Nariño, Colombia. PhD. Psychologist and psychotherapist. Researcher and specialist in online delivered interventions for mental health.E-mail: derek.richards@tcd.ie
A B S T R A C T

The worldwide penetration of the Internet and its related technologies, the rapid developments of new technologies and the pervasive use of technology in people's lives, are indicators that we live in a technological age. New technologies and their potential for use in psychological interventions and mental health services have not gone unnoticed. The last 15 years or so have witnessed the employment of new technologies in developing and delivering a variety of psychological interventions, these include information WebPages, internet-based computer programs that are addressed to treatment of specific problems, the use of mobile phones and games to help psychological practice, among others. However, while a broad range of technology-delivered psychological interventions have demonstrated success in high-income countries, little is known of their potential for countries such as Colombia. The paper begins with a brief history, followed by an overview of the field of technology-delivered psychological interventions. Lastly, the paper seeks to present a justification for the potential use of technologydelivered psychological interventions in Colombia.

Key words author

Psychological interventions, internet-delivered, psychological treatments,

technologies, online counseling

Key words plus

Clinical Psychology, Therapy Psychology

\section{RES UMEN}

La expansión mundial del Internet y tecnologías relacionadas, los rápidos desarrollos de las nuevas tecnologías y el uso perverso de la tecnología en la vida de las personas, son indicadores de que vivimos en una era tecnológica. Las nuevas tecnologías y su potencial uso en intervenciones psicológicas y los servicios de salud mental no han pasado desapercibidos. En los últimos 15 años más o menos hemos sido testigos del empleo de nuevas tecnologías en el desarrollo y distribución de una variedad de intervenciones psicológicas, que incluyen páginas web de información, programas informáticos disponibles en Internet que se dirigen al tratamiento de problemas específicos, el uso de teléfonos móviles y juegos para ayudar a la práctica psicológica, entre otros. Sin embargo, mientras que una amplia gama de intervenciones psicológicas basadas en tecnología han demostrado éxito en los países de altos ingresos, poco se sabe de su potencial para países como Colombia. El documento comienza con una breve historia, seguido de una visión general del campo de las intervenciones psicológicas basadas en tecnología. Por último, el documento busca presentar una justificación para el uso potencial de las intervenciones psicológicas basadas en tecnología entregados en Colombia. Palabras clave autores

Intervenciones psicológicas basadas en internet, tratamientos psicológicos, tecnologías, asesoría en línea.

Palabras clave adicionales

Psicología clínica, terapia psicológica. 


\section{Introduction}

Technology has become central in the conduct of our lives, for instance, most people now use email, whether as part of their work or for personal use. However, this is only the beginning of the impact that technological developments are having on our lives. For example, many, especially younger people, conduct a good portion of their lives online, through social networking sites and engaging and sharing through other virtual spaces such as Second Life.

Technological developments have not gone unnoticed by mental health services that have begun to realize the potential of employing technologydelivered psychological interventions, which can complement and extend the already existing service provision. It is the case that in the last 15 years or so, technologies have developed sufficiently to be employed safely in the service of mental health and well-being (Ritterband et al., 2003). Technologydelivered psychological interventions for mental health range from psycho-educational information online, online counseling, self-administered programs and the use of virtual reality systems for the treatment of specific disorders, multi-media delivered psychological interventions and the use of games and mobile phones that help in psychological treatments (Richards, 2008). The paper seeks to overview the field regarding technology-delivered psychological interventions.

The majority of developments and research regarding the use of technology-delivered psychological interventions has occurred in high-income countries such as the U.S., Europe and Australia. Little is known of the potential for development and use of such interventions in Colombia. Additionally, therefore, the paper seeks to present some justifications for the potential use of technology-delivered psychological interventions in Colombia.

\section{A Brief History}

Online self-help support groups (Kanani \& Regehr, 2003) appeared on the Internet as early as
1982. One early service was "Ask Uncle Ezra," a free service offered to students of Cornell University. Ivan Goldberg, M.D. began answering questions online about the medical treatment of depression during the early 1990s (Skinner \& Zack, 2004). John Grohol, DPsych, an early innovator developed an online mental health community website in 1995; he is still active in this area currently.

Although mainly composed of offering advice, fee-based mental health services began to appear about the mid-1990. The first known fee-based Internet mental health service was established by Sommers in 1995 offering longer-term asynchronous (email) therapy (Skinner \& Zack, 2004). Needham, in the mid-90s became the first practitioner to offer e-therapy synchronously via real time chat. By the late 1990's, online counseling services were emerging and these were often done through E-clinics. Such companies could provide therapists with a secure website, active marketing and other practice management tools (Skinner \& Zack, 2004).

The International Society for Mental Health Online (ISMHO) was founded in 1997 with the objective to promote the understanding, use and development of online information and communication technologies for the international mental health community. From its beginning the various technology-delivered psychological interventions have been criticized by professionals and laypeople alike, yet they have flourished. Barak, Klein and Proudfoot (2009) state that this is likely due to several factors including:

- Increasing acceptability of the internet as a legitimate social tool;

- Computer hardware and software developments (especially in relation to ease of use, privacy protection and online communication capabilities);

- Development of ethical guidelines by various professional organizations;

- Growing research; and

- Establishment of online training for professionals. 


\section{Technology-Delivered Psychological Interventions: An Overview}

Although a broad range of terms have been employed in order to describe the different uses of various technologies in psychological practice, for instance, e-mental health, e-therapy, online counseling, internet-based treatments, among others, for the purpose of this article I will use technologydelivered psychological interventions as a term that encompasses all.

The potential of the Internet has been realized by many in a multitude of different ways; beneficial and otherwise (Barak, 1999). Psychological practitioners and researchers have also considered the Internet as a vehicle for education and mental health service delivery (Goss \& Anthony, 2003; Richards, 2009). Technology-delivered psychological interventions are wide-ranging and include online psycho-educational materials (Barak, 1999) such as the virtual pamphlet collection (http:// www.dr-bob.org/vpc/).

Peer support, using discussion boards, has been successfully developed online for groups such as cancer patients, HIV patients, eating disorder patients and those suffering from depression (Darcy \& Dooley, 2007; Salem, Bogat \& Reid, 1997). The Internet has also been used for counseling online (Efstathiou, 2009; Goss \& Anthony, 2003; Richards, 2009). Different technologies have been employed including custom software packages, mobile phones, virtual reality and multimedia. The Internet is an attractive medium as it can support a variety of technological platforms and associated media. The pervasiveness of technology in people's lives is an additional motivation to engage with and develop various types of technology-delivered psychological interventions.

\section{Self-directed software}

Self-administered computer programs designed as treatment packages for specific disorders are mostly client-led, the user works though the program and its related exercises in the same way one might use a self-help book. "Beating the Blues" for depression and anxiety is one example (Marks, Cavanagh \& Gega, 2007). Beating the Blues is an eight-session, self-administered program that delivers CBT content through multimedia. It includes a series of filmed case studies of individuals modelling the symptoms of depression and the application of the CBT strategies. A voice-over guides the user through the sessions, online exercises, homework tasks and a printable post-session summary sheet is available (Cavanagh et al., 2006). A number of research studies have contributed to establishing its effectiveness (Marks et al., 2007).

The majority of such computer programs are self-directed; there is minimal therapist contact with users. Arguably, this has compromised its acceptance and usage; however, it has also been a point of benefit for users (Goss \& Anthony, 2003). However, users seem to benefit from any type of support by using such programs. For instance, a recent meta-analysis (Richards \& Richardson, 2012) of computer-based self-administered psychological treatments for depression demonstrates that supported programs yield larger effects than those without support. This is not to deny the benefits of unsupported programs, which are efficacious (Andersson \& Cuijpers, 2009; Newman, Szkodny, Llera \& Przeworski, 2011). Self-directed programs have been developed for depression, anxiety, PTSD and other mental health and health problems and their efficacy has been demonstrated (Marks et al., 2007).

\section{Mobile Phones}

Mobile phone usage is high, especially for young people. Short Message Service (SMS) has evolved to become a component of everyday live for billions of users worldwide. In counseling and therapy there are some tasks that can be administered using mobile phones. At its simplest, sending txt messages to make or break appointments. Another example is the use of a phone to record a mood diary. Matthews, Doherty, Sharry and Fitzpatrick (2008), for instance, developed an application that can be used in mobile phones and allows the client to record their mood during the day. The results are held 
on a database and as such the therapist can have a recording of the diary entry and when it was made.

A study by Shapiro et al. (2010) randomized children and adolescents with obesity to three groups: the first group used paper diaries; the second used an electronic diary from their mobile phone and a control group. The participants that used texting versus a paper diary to report on eating behavior demonstrated a lower attrition and greater adherence to the self-monitoring regime. Other studies have also used mobile phones to monitor clients and support their medication and therapeutic regime (Elliott, 2008; Pijnenborg, Withaar, Evans, Van Den Bosch \& Brouwer, 2007).

Other examples of the use of mobile phones are in delivering motivational messages to clients, or as a check-in for clients between sessions and also as a tool to support suicidal clients (Haszelwood, 2008). In these ways the phone can be used as an adjunct to therapy and support users' engagement.

Chipchase (2007) argues that SMS text messaging may be relevant to the emerging economies, where psychological services may be less well developed. One example is Africa, which is the fastest growing mobile phone market in the world, where a number of different projects have demonstrated the feasibility of reaching populations who have to date been poorly served by psychological services (Gadebe, 2006).

\section{Multimedia}

Multimedia is the use of a variety of media such as text, sound, animation and video. One example is the development of podcasts on relaxation techniques (http://tinyurl.com/62ngt8b) or delivering personal stories of student's experiences at university (http://tinyurl.com/62eb5cd). A more elaborate example is the use of hand crafted multimedia storytelling as an aid in the therapy process. 'Transforming Stories' it is essentially a multimedia toolkit where users can build their personal therapeutic story. The program provides an opportunity to engage adolescents and young adults in therapy (Brosnan, Sharry, Fitzpatrick \& Boyle, 2006).

\section{Gaming}

Computer games are interactive and fun; surveys in the U.K. and U.S. have reported that teenagers rate computer games as their number one entertainment. Research has demonstrated that the use of games therapeutically can help to engage clients (Coyle \& Matthews, 2004), improve session attendance and reduce the stigma associated with attendance (Clark \& Schoech, 1984). Studies have reported that therapeutic games have helped adolescents to develop more self-confidence and responsibility (Hyland, Kenyon, Allen \& Howarth, 1993) and helped children to displace their aggression through developing coping and problem solving skills (Gardner, 1991).

Researchers have developed therapeutic games to use with adolescents in therapy. The games are based on a range of different therapeutic approaches and clinical issues. Examples include: 'Private Investigator (PI)' (Coyle \& Matthews, 2004) which is a solution focused approach to problem solving. In PI a young person can train as a detective, learning skills and strategies that will help them find solutions to problems. Another example is 'Temper Quest', here users visit the temper lab and explore aspects of their temper and its impact on their lives, this game follows a protocol of narrative therapy (Coyle \& Matthews, 2004).

\section{Virtual Reality}

Understanding the possibilities of virtual reality for psychological interventions, researchers in Italy and Spain have developed virtual worlds that allow users to address issues such as anxiety and phobias (Baños et al., 2009). A virtual reality (VR) system is the combination of hardware and software that enables its developers to create synthetic life-like experiences. The virtual world can be a model of a real world object such as a house, or spiders, or it can be a representation of an abstract world or a completely imaginary world.

One example is Emma's world, which is an adaptable virtual reality system that can be used for different problems. For instance a person work- 
ing with grief can over time populate the virtual world with objects of meaning associated with the deceased such as photographs, music, video clips, all of which have personal emotional resonance and can be worked within the therapeutic process.

In the last 15 years virtual reality systems have been developed to treat anxiety disorders, phobias, panic disorders and post-traumatic stress disorders (Riva, 2005). Emerging applications of VR include sexual disorders (Optale, Marin, Pastore, Nasta \& Pianon, 2003), pain management (Hoffman, 2004), addictions (Bordnick, Graap, Copp, Brooks \& Ferrer, 2005), stress management (Villani, Riva \& Riva, 2007) and eating disorders (Riva et al., 2006).

\section{Online counseling}

Online counseling is defined as the delivery of therapeutic interventions in cyberspace where communication between a trained professional, counselor and client(s) is facilitated using computer-mediated communication (CMC) technologies (Richards \& Viganó, 2012). Online counseling can be conducted asynchronously (e-mail), which is time-delayed between a users submission and a counselor's reply, or delivered synchronously (chat, videoconferencing), which is live and occurs in real-time.

Online counseling has been provided as a standalone service and as an adjunct to other services (Efstathiou, 2009; Richards, 2009). Indeed, some computer-based self-administered treatments for a variety of disorders have included online counseling support, usually in the form of asynchronous post-sessions feedback, which appears to increase adherence and yield enhanced outcomes (Newman et al., 2011; Richards \& Richardson, 2012).

The findings from research studies in the area of synchronous and asynchronous online counseling have positively evaluated outcomes, working alliance, helpfulness and impact and report client improvement and satisfaction (e.g.: Barak \& Bloch, 2006; Barak, Hen, Boniel-Nissim \& Shapira, 2008; Cook \& Doyle, 2002; Day \& Schneider, 2002; Efstathiou, 2009; Hanley, 2009; Knaevelsrud \& Maercker, 2006; Leibert, Archer, Munson \& York, 2006; Richards, 2009).
The practice of online counseling brings with it various distinct advantages, such as convenience and the ability to overcome the existing psychological and physical barriers that individuals can face in accessing counseling (Mallen, Vogel, Rochlen \& Day, 2005; Rochlen, Zack \& Speyer, 2004). It also has some distinct challenges, which have appeared in the online counseling literature from the early days (Childress, 1998). There are many features and cyber behaviors characteristic of online counseling, such as Disinhibition, the loss of verbal and audio cues and writing behavior and expression online (Fenichel et al., 2002; Sheese, Brown \& Graziano, 2004; J. Suler, 2004; J. R. Suler, 2002; Richards \& Viganó, 2012).

\section{Innovation in Service Delivery: Advantages \& Limitations}

The overview will give the reader some notion of what has already been spawned regarding technology-delivered psychological interventions. Research outcomes have been positive and, as a result, the work continues (Marks et al., 2007; Rochlen et al., 2004).

The advantages of engaging technology are many and include the potential to complement and extend the current service provision and increase the access to services for a greater number and range of people. For example clinicians and researchers in Scotland have successfully used videoconferencing technology to provide a muchneeded therapeutic service to a remote group for eating disorders in the nearby Shetland Islands (Simpson, Bell, Knox \& Mitchell, 2005). Extending access includes geographical access, access to people with disabilities and access to populations who does not seek the needed help because of their condition. The benefits may contribute to counter-balancing the current inequity of service availability and access.

At the same time there are also potential obstacles. One issue is the clinical assessment of individuals using technology-delivered psychological interventions. Often psychologists rely on self-reports, which can be inaccurate. Therefore, can accurate 
assessments be made and consequently the correct treatment delivered? In its defence many research studies have reported success by assessing clients online and thereafter have reported successful outcomes for a range of disorders (Marks et al., 2007). Further research has demonstrated no difference with Internet versus paper-and-pencil administrations of commonly used instruments for assessment (Carlbring et al., 2007).

Unless provided by a reputable source it is difficult to monitor the quality of information or interventions being made available and also to guard against the potential naivety and vulnerability of users; especially in the case of younger users.

Transferring psychological support services online is controversial and raises many concerns. Among these, there are questions about crisis management, anonymity, ethical and clinical responsibility, user safety, technical security, retention and completion of treatments (Rochlen et al., 2004; Tate \& Zabinski, 2004), although in recent years many of these concerns have been addressed adequately (Barak, 2009).

\section{A justification for the use of technology in mental health in Colombia}

Technology-delivered psychological interventions have demonstrated their efficacy in high-income countries. Some work has been carried out in Latin American countries. Cardenas-Lopez and colleagues at the Laboratorio de Enseñanza Virtual y Ciberpsicología, UNAM, Mexico DF, have investigated about the use of virtual reality for the treatment of phobias and post-traumatic stress. Another study reported positive outcomes using a computer-based program to treat depression and cognitive impairment in students, however the sample was small (Alvarez, Sotres, León, Estrella \& Sosa, 2008).

In Colombia is there evidence to argue for the implementation and research of innovative technology-delivered psychological interventions? The following points provide some justifications for the case. To begin with, Bogotá's Plan de Salud del Distrito Capital 2008 - 2012 (2008) recognizes the need to develop an appropriate health and mental health services so that individuals can achieve a good quality of life, including guaranteeing the right to mental health (p. 33). However, the reality is far from the policy ideal. Some cities in Colombia have community psychological services, but most do not.

Epidemiological research has highlighted the extent of significant psychopathology in Colombia and levels are not far removed from those found in high-income countries (Gómez-Restrepo et al., 2004; Ministerio de Protección Social, 2003; Richards, 2011). Therefore it is clear that a need exists for psychological services.

However, barriers exist for potential users; these include the costs of such services and personal stigma that can prevent those from seeking help when they need it. Between 85-95\% of individuals with mental health problems in Colombia do not access or cannot access the services that they require (Ministerio de Protección Social, 2003). Of those that may seek the help they need, they are met with a shortage of trained professionals and consequent waiting lists, which of course contradicts the benefits of early intervention (Royal College of Psychiatrists, 2003). The situation is not unusual or indeed very different from the barriers and difficulties that are faced by psychological services in other countries in Latin America, U.S. and Europe.

Consequently, the services that are available are severely overburdened and the visible demand that does exist cannot be adequately served.

It is for these and other reasons that technologydelivered psychological interventions have grown. Many researchers and clinicians have argued for their potential to provide the needed interventions that can ameliorate the situation against high demands, lack of service development, shortages of trained professionals, costs and personal barriers such as stigma. Europe, the U.S. and Australia have benefitted from the potential of innovative service delivery.

Additionally, Internet access in Colombia is 50\%. Many, especially younger people, are high users of the Internet and its related technologies. For instance a recent survey (http://tinyurl. com/3t9vavu) at UAN asked students to rate the 
number of times they access social networking sites per day. After one month (18/08 to 18/09 2011) 579 responses have been collected, 145 (25\%) have reported accessing social networks 5 times per day and 137 (24\%) have reported accessing such sites 2-5 times per day.

There is the possibility that such technology-delivered services may appeal to the technology savvy. For Colombia, therefore, for the reasons outlined above, may be appropriate to benefit from different technology-delivered psychological interventions.

\section{References}

Alvarez, L. M., Sotres, J. F. C., León, S. O., Estrella, J. \& Sosa, J. J. S. (2008). Computer program in the treatment for major depression and cognitive impairment in university students. Computers in Human Behavior, 24(3), 816-826. doi: 10.1016/j. chb.2007.02.013

Andersson, G. \& Cuijpers, P. (2009). Internet-based and other computerized psychological treatments for adult depression: A meta-analysis. Cognitive Behaviour Therapy, 38(4), 196-205. doi:10.1080/16506070903318960

Baños, R. M., Botella, C., Guillen, V., Garcia-Palacios, A., Quero, S., Bretán-Lápez, J., et al. (2009). An adaptive display to treat stress-related disorders: EMMA's World. British Journal of Guidance $\mathcal{E}^{2}$ Counselling, 37(3), 347-356.

Barak, A. (1999). Psychological application on the internet: A Discipline on the threshold of a new millennium. Applied $\mathcal{E}$ Preventive Psychology, 8(4), 231-245.

Barak, A. \& Bloch, N. (2006). Factors related to perceived helpfulness in supporting highly distressed individuals through an online support chat. CyberPsychology Ë Behavior, 9(1), 60-68.

Barak, A., Hen, L., Boniel-Nissim, M. \& Shapira, N. (2008). A comprehensive review and a metaanalysis of the effectiveness of internet-based psychotherapeutic Interventions. Journal of Technology in Human Services, 26(2), 109-160. doi: 10.1080/15228830802094429

Barak, A., Klein, B. \& Proudfoot, J. (2009). Defining internet-supported therapeutic interventions. An- nals of Behavioral Medicine, 38(1), 4-17. doi:10.1007/ s12160-009-9130-7

Bordnick, P. S., Graap, K., Copp, H. L., Brooks, J. \& Ferrer, M. (2005). Virtual reality cue reactivity assessment in cigarette smokers. CyberPsychology EF Behavior, 8(5), 487-492.

Brosnan, E., Sharry, J., Fitzpatrick, C. \& Boyle, R. (2006). An evaluation of the integrated use of a multimedia storytelling system within a psychotherapy intervention for adolescents. In Proceedings of the 2006 Conference on Human Factors in Computing Systems (pp. 598-603). New York: Association for Computing Machinery. doi:10.1145/1125451.1125576

Carlbring, P., Brunt, S., Bohman, S., Austin, D., Richards, J., Ost, L., et al. (2007). Internet vs. paper and pencil administration of questionnaires commonly used in panic/agoraphobia research. Computers in Human Behavior, 23(3), 1421-1434. doi: 10.1016/j. chb.2005.05.002

Cavanagh, K., Shapiro, D. A., Van Den Berg, S., Swain, S., Barkham, M. \& Proudfoot, J. (2006). The effectiveness of computerized cognitive behavioural therapy in routine care. British Journal of Clinical Psychology, 45(4), 499-514. doi: 10.1348/014466505x84782

Clark, B. \& Schoech, D. (1984). A computer-assisted computer game for adolescents: Initial development and comments. In M. D. Schwartz (Ed.), Using computers in clinical practice: Psychotherapy and mental health applications (pp. 335-353). New York: Haworth Press.

Cook, J. E. \& Doyle, C. (2002). Working alliance in online therapy as compared to face-to-face therapy: Preliminary results. CyberPsychology $\mathbb{E}$ Behavior, 5(2), 95-105. doi:10.1089/109493102753770480

Coyle, D. \& Matthews, M. (2004, April). Personal investigator: A therapeutic 3D game for teenagers. Paper presented at the Social Learning Through Gaming Workshop, Vienna, Austria.

Childress, C. (1998). Potential risks and benefits of online psychotherapeutic interventions. International Society for Mental Health Online. Retrieved 24 June, 2011, from http://www.ismho.org/issues/9801.htm

Chipchase, T. (2007, October). Jan Chipchase on mobile phones. TED. Ideas worth spreading. Retrieved 25 
October, 2011, from http://www.ted.com/talks/ jan_chipchase_on_our_mobile_phones.html

Darcy, A. M. \& Dooley, B. (2007). A clinical profile of participants in an online support group. European Eating Disorders Review, 15(3), 185-195. doi: 10.1002/erv.775

Day, S. X. \& Schneider, P. L. (2002). Psychotherapy using distance technology: A comparison of faceto-face, video and audio treatment. Journal of Counselling Psychology, 49(4), 499-503.

Efstathiou, G. (2009). Students' psychological web consulting: Function and outcome evaluation. British Journal of Guidance E Counselling, 37(3), 243-255.

Elliott, J. (2008, December). Monitoring mental health by text. Health reporter, BBC News. Retrieved 25 October, 2011, from http://news.bbc.co.uk/2/hi/ health/7797155.stm

Fenichel, M., Suler, J., Barak, A., Zelvin, E., Jones, G., Munro, K., et al. (2002). Myths and realities of online clinical work. CyberPsychology $\mathcal{E}$ Behavior, 5(5), 481-497. doi: 10.1089/109493102761022904

Gadebe, T. (2006, February). SMS help for teens in distress. SouthAfrica.info. Retrieved 25 October, 2011, from http://www.southafrica.info/services/ health/teensindistress.htm

Gardner, J. E. (1991). Can the Mario Bros help? Nintendo games as an adjunct in psychotherapy with children. Psychotherapy, 28(4), 667-670.

Gómez-Restrepo, C., Bohórquez, A., Pinto Masis, D., Gil Laverde, J. F. A., Rondón Sepúlveda, M., et al. (2004). The prevalence of and factors associated with depression in Colombia. Revista Panamericana de Salud Pública, 16(6), 378-386.

Goss, S. \& Anthony, K. (Eds.). (2003). Technology in counselling and psychotherapy: A practitioner's guide. London: Palgrave Macmillan.

Hanley, T. (2009). The working alliance in online therapy with young people: Preliminary findings. British Journal of Guidance $\mathcal{E}$ Counselling, 37(3), 257-269. doi:10.1080/03069880902956991

Haszelwood, A. (2008). Using text messaging in the treatment of eating disorders. Nursing Times, 104(40), 28-29.

Hoffman, H. (2004). Virtual-Reality Therapy. Scientific American. Available at http://www. sciamdigital.com/index.cfm? fa $=$ Products.
View Is suePreview \& A RT ICLEID_ $\mathrm{CHAR}=\mathrm{A} 4 \mathrm{BFFC} 51-2 \mathrm{~B} 35-221 \mathrm{~B}-69 \mathrm{DB}$ 2D5A63160CD5

Hyland, M. E., Kenyon, C. A., Allen, R. \& Howarth, P. (1993). Diary keeping in asthma: Comparison of written and electronic methods. British Medical Journal, 306(6876), 487-489. doi:10.1136/ bmj.306.6876.487

Kanani, K. \& Regehr, C. (2003). Clinical, ethical and legal issues in e-therapy. Families in Society, 84(2), 156-162. doi:10.1606/1044-3894.98

Knaevelsrud, C. \& Maercker, A. (2006). Does the quality of the working alliance predict treatment outcome in online psychotherapy for traumatized patients? Journal of Medical Internet Treatment, 8(4), e31.

Leibert, T., Archer, J., Munson, J. \& York, G. (2006). An exploratory study of client perceptions of internet counseling and the therapeutic alliance. Journal of Mental Health Counseling, 28(1), 69-83.

Mallen, M. J., Vogel, D. L., Rochlen, A. B. \& Day, S. X. (2005). Online counseling: Reviewing the literature from a counseling psychology framework. The Counseling Psychologist, 33(6), 819-871.

Marks, I. M., Cavanagh, K. \& Gega, L. (2007). Hands on help: Computer-aided psychotherapy (Vol. 49). Hove: Psychology Press.

Matthews, M., Doherty, G., Sharry, J. \& Fitzpatrick, C. (2008). Mobile phone mood charting for adolescents. British Journal of Guidance $\mathcal{E}$ Counselling, 36(2), 113-129.

Ministerio de Protección Social. (2003). Informe sobre un panorama nacional de la salud y la enfermedad un trabajo en Colombia. Bogotá, Col: Author.

Newman, M. G., Szkodny, L. E., Llera, S. J. \& Przeworski, A. (2011). A review of technology-assisted self-help and minimal contact therapies for anxiety and depression: Is human contact necessary for therapeutic efficacy? Clinical Psychology Review, 31(1), 89-103. doi:10.1016/j.cpr.2010.09.008

Optale, G., Marin, S., Pastore, M., Nasta, A. \& Pianon, C. (2003). Male sexual dysfunctions and multimedia immersion therapy. CyberPsychology $\mathbb{E}$ Behavior, 6(3), 289-294. doi:10.1089/109493103322011588

Pijnenborg, G. H. M., Withaar, F. K., Evans, J. J., Van Den Bosch, R. J. \& Brouwer, W. H. (2007). SMS 
text messages as a prosthetic aid in the cognitive rehabilitation of schizophrenia. Rehabilitation Psychology, 52(2), 236-240.

Richards, D. (2008). 'The future isn't what it used to be': Technology in counselling and psychotherapy. Eisteach, 3, 15-23.

Richards, D. (2009). Features and benefits of online counselling: Trinity College online mental health community. British Journal of Guidance $\mathbb{E}$ Counselling, 37(3), 231-242. doi:10.1080/03069880902956975

Richards, D. (2011). Prevalence and clinical course of depression: A review. Clinical Psychology Review, 31(7), 1117-1125. doi:10.1016/j.cpr.2011.07.004

Richards, D. \& Richardson, T. (2012). Computerbased psychological treatments for depression: A systematic review and meta-analysis. Clinical Psychology Review, 32(4), 329-342. doi: 10.1016/j. cpr.2012.02.004

Richards, D. \& Viganó, N. (2012). Online Counseling. In Y. Zheng (Ed.), Encyclopedia of Cyber Behavior: (3 Vol.) (Vol. 1, pp. 699-713). New York: IGI Global.

Ritterband, L. M., Gonder-Frederick, L. A., Cox, D. J., Clifton, A. D., West, R. W. \& Borowitz, S. M. (2003). Internet interventions: In review, in use and into the future. Professional Psychology: Research Ë Practice, 34(5), 527-534.

Riva, G. (2005). Virtual reality in psychotherapy: A review. CyberPsychology \& Behavior, 8(3), 220-230.

Riva, G., Bacchetta, M., Cesa, G., Conti, S., Castelnuovo, G., Mantovani, F., et al. (2006). Is severe obesity a form of addiction? Rationale, clinical approach and controlled clinical trial. CyberPsychology $\mathcal{E}$ Behavior, 9(4), 457-479.

Rochlen, A. B., Zack, J. S. \& Speyer, C. (2004). Online therapy: Review of relevant definitions, debates and current empirical support. Journal of Clinical Psychology, 60(3), 269-283. doi: 10.1002/jclp.10263
Royal College of Psychiatrists. (2003). The mental health of students in higher education. London: Author.

Salem, D. A., Bogat, G. A. \& Reid, C. (1997). Mutual help goes on-line. Journal of Community Psychology, 25(2), 189-207.

Secretaría Distrital de Salud. (2008). Plan de Salud del Distrito Capital 2008-2012. Bogotá, DC: Author.

Shapiro, J. R., Bauer, S. andrews, E., Pisetsky, E., BulikSullivan, B., Hamer, R. M., et al. (2010). Mobile therapy: Use of text-messaging in the treatment of bulimia nervosa. International Journal of Eating Disorders, 43(6), 513-519. doi:10.1002/eat.20744

Sheese, B. E., Brown, E. L. \& Graziano, W. G. (2004). Emotional expression in cyberspace: Searching for moderators of the pennebaker disclosure effect via e-mail. Health Psychology, 23(5), 457-464. doi: 10.1037/0278-6133.23.5.457

Simpson, S., Bell, L., Knox, J. \& Mitchell, D. (2005). Therapy via videoconferencing: A route to client empowerment? Clinical Psychology 8 Psychotherapy, 12(2), 156-165. doi: 10.1002/cpp.436

Skinner, A. \& Zack, J. S. (2004). Counseling and the Internet. American Behavioural Scientist, 48(4), 434-446.

Suler, J. (2004). The online disinhibition effect. CyberPsychology EF Behavior, 7(3), 321-326. doi: 10.1089/1094931041291295

Suler, J. R. (2002). Identity management in cyberspace. Journal of Applied Psychoanalytic Studies, 4(4), 455 459.

Tate, D. F. \& Zabinski, M. F. (2004). Computer and Internet applications for psychological treatment: Update for clinicians. Journal of Clinical Psychology, 60(2), 209-220.

Villani, D., Riva, F. \& Riva, G. (2007). New technologies for relaxation: The role of presence. International Journal of Stress Management, 14(3), 260-274. 
